\title{
REVIEW
}

\section{Hypokalemia: a clinical update}

\section{Efstratios Kardalas ${ }^{1}$, Stavroula A Paschou ${ }^{2}$, Panagiotis Anagnostis ${ }^{3}$, Giovanna Muscogiuri $^{4}$, Gerasimos Siasos $^{5}$ and Andromachi Vryonidou 6}

${ }^{1}$ Department of Endocrinology and Diabetes, Evangelismos Hospital, Athens, Greece

2Division of Endocrinology and Diabetes, 'Aghia Sophia' Hospital, Medical School, National and Kapodistrian University of Athens, Athens, Greece

${ }^{3}$ Unit of Reproductive Endocrinology, First Department of Obstetrics and Gynecology, Medical School, Aristotle University of Thessaloniki,

Thessaloniki, Greece

${ }^{4}$ Division of Endocrinology, Department of Clinical Medicine and Surgery, 'Federico II' University of Naples, Naples, Italy

${ }^{5}$ First Department of Cardiology, Hippokration Hospital, Medical School, National and Kapodistrian University of Athens, Athens, Greece

${ }^{6}$ Department of Endocrinology and Diabetes, Hellenic Red Cross Hospital, Athens, Greece

Correspondence should be addressed to A Vryonidou: mahi_vr@hotmail.com

\begin{abstract}
Hypokalemia is a common electrolyte disturbance, especially in hospitalized patients. It can have various causes, including endocrine ones. Sometimes, hypokalemia requires urgent medical attention. The aim of this review is to present updated information regarding: (1) the definition and prevalence of hypokalemia, (2) the physiology of potassium homeostasis, (3) the various causes leading to hypokalemia, (4) the diagnostic steps for the assessment of hypokalemia and (5) the appropriate treatment of hypokalemia depending on the cause. Practical algorithms for the optimal diagnostic, treatment and follow-up strategy are presented, while an individualized approach is emphasized.
\end{abstract}

\section{Introduction}

Hypokalemia is present when serum levels of potassium are lower than normal. It is a rather common electrolyte disturbance, especially in hospitalized patients, with various causes and sometimes requires urgent medical attention (1). It usually results from increased potassium excretion or intracellular shift and less commonly from reduced potassium intake. Although many chapters, clinical statements and guidelines refer to hypokalemia, they do so, mainly in the context of other clinical entities. The aim of this comprehensive review is to provide current knowledge regarding definition, prevalence and etiology of hypokalemia, as well as, an individualized guide for the optimal diagnostic management and follow-up strategy.

\section{Materials and methods}

In order to identify publications on hypokalemia, a literature search was conducted in PubMed using combinations of the key-terms: 'potassium' OR 'hypokalemia' OR 'hypokalaemia' OR 'electrolyte disturbances' AND 'guide' OR 'algorithm' OR 'guidelines'. In addition, a manual search of key journals and abstracts from the major annual meetings in the fields of endocrinology and nephrology was conducted. This review collected, analyzed and qualitatively re-synthesized information regarding: (1) the definition and prevalence of hypokalemia, (2) the physiology of potassium homeostasis, (3) the various causes leading to hypokalemia, (4) the diagnostic steps for the assessment of hypokalemia and (5) the appropriate treatment of hypokalemia depending on the cause.

\section{Physiology of potassium homeostasis \\ Potassium role in cellular functions}

Potassium $\left(\mathrm{K}^{+}\right)$plays a key role in maintaining normal cell function (2). $\mathrm{K}^{+}$is the main intracellular cation

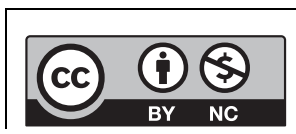

This work is licensed under a Creative Commons Attribution-NonCommercial 4.0 International License. 
and almost all cells have the pump called ${ }^{\prime} \mathrm{Na}^{+}-\mathrm{K}^{+}$ATPase', which pumps sodium $\left(\mathrm{Na}^{+}\right)$out of the cell and $\mathrm{K}^{+}$into the cell leading to a $\mathrm{K}^{+}$gradient across the cell membrane $\left(\mathrm{K}^{+}{ }_{\text {in }}>\mathrm{K}^{+}{ }_{\text {out }}\right)$, which is partially responsible for maintaining the potential difference across membrane. Many cell functions rely on this potential difference, particularly in excitable tissues, such as nerve and muscle. Two percent of $\mathrm{K}^{+}$exists in the extracellular fluid (ECF) at a concentration of only $4 \mathrm{mEq} / \mathrm{L}$ (3). Enzyme activities, as well as, cell division and growth are catalyzed by potassium and are affected by its concentrations and its alterations.

Of great importance, intracellular $\mathrm{K}^{+}$participates in acid-base regulation through exchange for extracellular hydrogen ions $\left(\mathrm{H}^{+}\right)$and by influencing the rate of renal ammonium production (4). Counterregulatory mechanisms exist in order to defend against potassium alterations. These mechanisms serve to maintain a proper distribution of $\mathrm{K}^{+}$within the body, as well as to regulate the total body $\mathrm{K}^{+}$content. Excessive ECF potassium (hyperkalemia) decreases membrane potential, while hypokalemia causes hyperpolarization and non-responsiveness of the membrane (5). If potassium balance is disrupted (hypokalemia or hyperkalemia), this can also lead to disruption of heart electrical conduction, dysrhythmias and even sudden death. Potassium balance has a direct negative effect on $\left(\mathrm{H}^{+}\right)$balance at intracellular and extracellular level and the overall cellular activity.

\section{Balance of $\mathbf{K}^{+}$}

External potassium balance is determined by the rate of potassium intake (normally $100 \mathrm{mEq} /$ day) and rate of urinary (normally $90 \mathrm{mEq} /$ day) and fecal excretion (normally $10 \mathrm{mEq} /$ day). The distribution of potassium in muscles, bone, liver and red blood cells (RBC) and ECF has a direct effect on internal potassium balance $(6,7)$ (Fig. 1).

The kidney is primarily responsible for maintaining total body $\mathrm{K}^{+}$balance. However, renal $\mathrm{K}^{+}$excretion is adjusted over several hours; therefore, changes in extracellular $\mathrm{K}^{+}$concentrations are initially buffered by movement of $\mathrm{K}^{+}$into or out of skeletal muscle. The regulation of $\mathrm{K}^{+}$distribution between the intracellular and extracellular space is referred to as internal $\mathrm{K}^{+}$balance. Under normal conditions, insulin and catecholamines play the most important role in this regulation (8). Potassium controls its own ECF concentrations through a feedback regulation of aldosterone release. An increase in $\mathrm{K}^{+}$levels leads to a release of aldosterone through the renin-angiotensin-aldosterone mechanism or through the direct release of aldosterone from the adrenal cortex cells, which are stimulated (9). More specifically, an increase in extracellular potassium concentrations stimulates aldosterone secretion (via angiotensin II), which in turn increases urinary $\mathrm{K}^{+}$ excretion. In the steady state, $\mathrm{K}^{+}$excretion matches intake and approximately $90 \%$ is excreted by the kidneys and $10 \%$ in the stool fairly constant. By contrast, the

\section{Potassium Homeostasis}

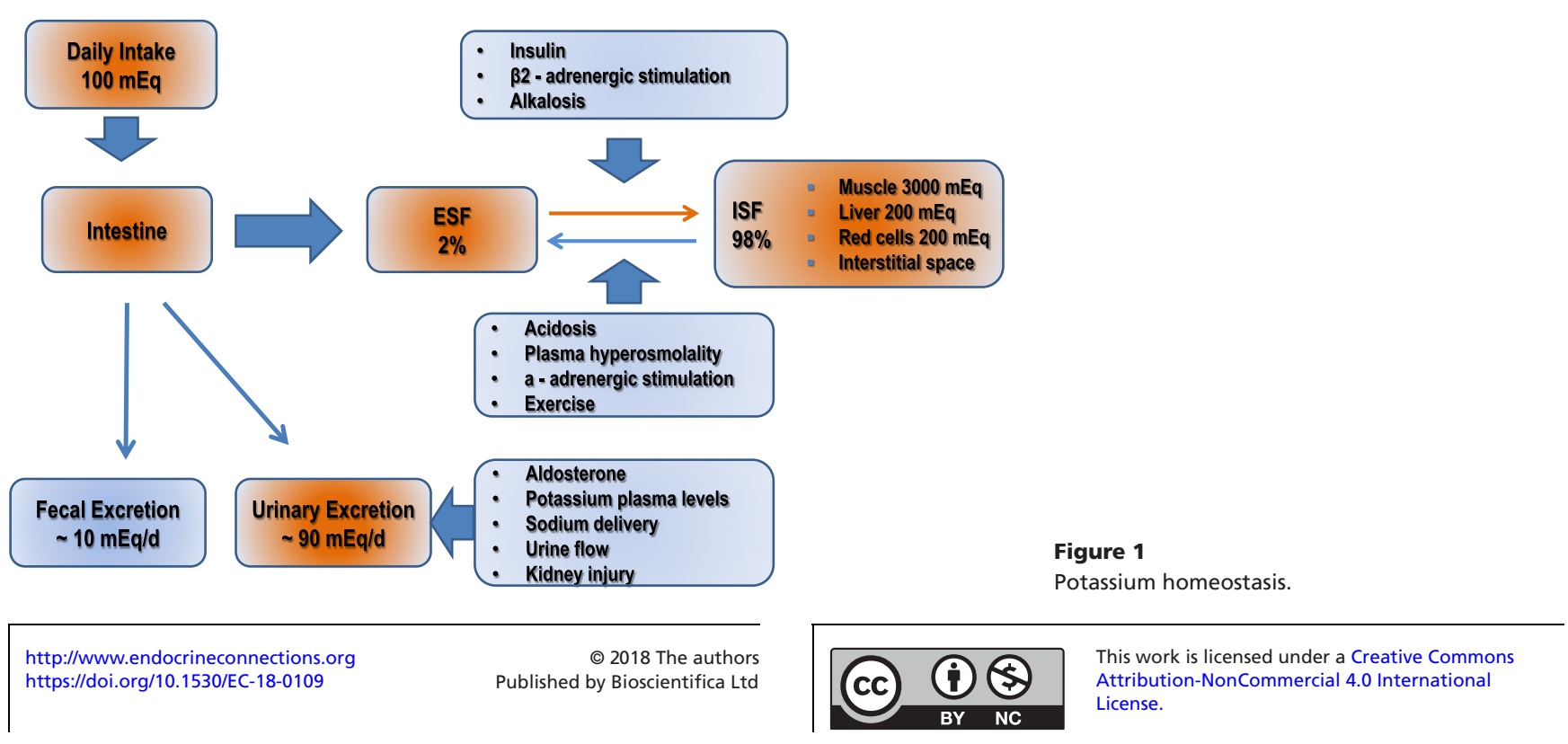


rate of $\mathrm{K}^{+}$secretion by the distal nephron varies and is regulated according to the physiological needs. The cellular determinants of $\mathrm{K}^{+}$secretion in the principal cell include the intracellular $\mathrm{K}^{+}$concentration, the luminal $\mathrm{K}^{+}$concentration, the potential (voltage) difference across the luminal membrane and the permeability of the luminal membrane for $\mathrm{K}^{+}$. Conditions that increase cellular $\mathrm{K}^{+}$concentration, decrease luminal $\mathrm{K}^{+}$ concentration or render the lumen more electronegative will increase the rate of $\mathrm{K}^{+}$secretion. Conditions that increase the permeability of the luminal membrane for $\mathrm{K}^{+}$will increase the rate of $\mathrm{K}^{+}$secretion $(8,9)$.

Two principal determinants of $\mathrm{K}^{+}$secretion are mineralocorticoid activity and distal delivery of $\mathrm{Na}^{+}$ and water. Aldosterone is the major mineralocorticoid in humans and mediates the renal excretion of $\mathrm{K}^{+}$and $\mathrm{Na}^{+}$reabsorption by binding to the mineralocorticoid receptors in the distal tubules and collecting ducts of the nephron. Aldosterone increases intracellular $\mathrm{K}^{+}$ concentration by stimulating the activity of the $\mathrm{Na}^{+}$$\mathrm{K}^{+}$-ATPase in the basolateral membrane, stimulates $\mathrm{Na}^{+}$reabsorption across the luminal membrane, which increases the electronegativity of the lumen, thereby increasing the electrical gradient favoring $\mathrm{K}^{+}$secretion and lastly has a direct effect on the luminal membrane to increase $\mathrm{K}^{+}$permeability (10). Under conditions of volume depletion, activation of the renin-angiotensin system leads to increased aldosterone release. The increase in circulating aldosterone stimulates renal $\mathrm{Na}^{+}$retention, contributing to the restoration of ECF volume, but occurs without a demonstrable effect on renal $\mathrm{K}^{+}$secretion. When hyperkalemia occurs, aldosterone release is mediated by a direct effect of $\mathrm{K}^{+}$on cells in the zona glomerulosa. The subsequent increase in circulating aldosterone stimulates renal $\mathrm{K}^{+}$secretion, restoring the serum $\mathrm{K}^{+}$concentration to normal, but does so without concomitant renal $\mathrm{Na}^{+}$ retention. The ability of aldosterone to signal the kidney to stimulate salt retention without $\mathrm{K}^{+}$secretion in volume depletion and stimulate $\mathrm{K}^{+}$secretion without salt retention in hyperkalemia has been referred to as the aldosterone paradox (11).

Furthermore, $\mathrm{K}^{+}$is freely filtered by the glomerulus and almost all the filtered $\mathrm{K}^{+}$is reabsorbed in the proximal tubule and loop of Henle. This absorption in the proximal part of the nephron passively follows that of $\mathrm{Na}^{+}$and water, whereas reabsorption in the thick ascending limb of the loop of Henle is mediated by the $\mathrm{Na}^{+}, \mathrm{K}^{+}$and 2 chloride $\left(\mathrm{Cl}^{-}\right)$carrier (NKCC2) in the luminal membrane. The connecting segment, the principal cells in the cortical and outer medullary collecting tubule, and the papillary (or inner medullary) collecting duct via luminal potassium channels secrete $\mathrm{K}+(12)$. The renal outer medullary $\mathrm{K}^{+}$(ROMK) channel is one of the two populations of $\mathrm{K}^{+}$channels, which have been identified in the cells of the cortical collecting duct and is considered to be the major $\mathrm{K}^{+}$-secretory pathway. This channel is characterized by having low conductance and a high probability of being open under physiologic conditions. The maxi- $\mathrm{K}^{+}$ channel (also known as the large-conductance $\mathrm{K}^{+}(\mathrm{BK})$ channel) is characterized by a large single channel conductance and quiescence in the basal state and activation under conditions of increased flow. In addition to increased delivery of $\mathrm{Na}^{+}$and dilution of luminal $\mathrm{K}^{+}$concentration, recruitment of maxi- $\mathrm{K}^{+}$ channels contributes to flow-dependent increased $\mathrm{K}^{+}$ secretion $(11,12)$.

Returning to the function of the collecting segments, they secrete varying quantities of $\mathrm{K}^{+}$according to physiologic requirements and are responsible for most of the urinary potassium excretion. Secretion in the distal segments is also balanced by $\mathrm{K}^{+}$reabsorption through the intercalated cells in the cortical and outer medullary collecting tubules (13). The active $\mathrm{H}^{+}-\mathrm{K}^{+}$-ATPase pump in the luminal membrane acts as a mediator and leads to both proton secretion and $\mathrm{K}^{+}$reabsorption. The kidneys are far more capable in increasing than decreasing $\mathrm{K}^{+}$ excretion. As a result, inadequate intake can lead to $\mathrm{K}^{+}$ depletion and hypokalemia. Hyperkalemia usually occurs when renal excretion is impaired (glomerular filtration rate $(\mathrm{GFR})<20 \mathrm{~mL} / \mathrm{min})$.

\section{Definition and prevalence of hypokalemia}

Hypokalemia is an electrolyte characterized by low serum potassium concentrations (normal range: $3.5-5.0 \mathrm{mEq} / \mathrm{L}$ ). Severe and life-threatening hypokalemia is defined when potassium levels are $<2.5 \mathrm{mEq} / \mathrm{L}$. In outpatient population undergoing laboratory testing, mild hypokalemia can be found in almost $14 \%$ (14). Furthermore, as many as $20 \%$ of hospitalized patients are found to have hypokalemia but only in $4-5 \%$ this is clinically significant (15). Severe hypokalemia is relatively uncommon. Approximately $80 \%$ of patients who are receiving diuretics become hypokalemic, while many of patients with hypokalemia could also have an associated systemic disease. There are no significant differences in its prevalence between males and females (16). 


\section{Causes of hypokalemia}

Hypokalemia can be caused either by decreased intake of potassium or by excessive losses of potassium in the urine or through the GI tract $(17,18)$. The latter is more common. Excessive excretion of potassium in the urine (kaliuresis) may result from the use of diuretic drugs, endocrine diseases such as primary hyperaldosteronism, kidney disorders and genetic syndromes affecting the renal function (19). Gastrointestinal losses of potassium usually are due to prolonged diarrhea or vomiting, chronic laxative abuse, intestinal obstruction or infections. An intracellular shift of the potassium can also lead to severe hypokalemia. Insulin administration, stimulation of the sympathetic nervous system, thyreotoxicosis and familiar periodic paralysis are some of the reasons for this phenomenon (20). Congenital adrenal hyperplasia due to enzymatic defects is a genetic syndrome strongly associated with hypertension and hypokalemia, resulting from excessive mineralocorticoid effects. Drugs, such as diuretics and penicillin can be often the underlying cause of hypokalemia. Finally, hypomagnesemia is very important. More than $50 \%$ of clinically significant hypokalemia has concomitant magnesium deficiency and is clinically most frequently observed in individuals receiving loop or thiazide diuretic therapy. Concomitant magnesium deficiency has long been appreciated to aggravate hypokalemia. Hypokalemia associated with magnesium deficiency is often refractory to treatment with $\mathrm{K}^{+}$(21) (Table 1).

\section{Signs and symptoms}

The severity of hypokalemia's clinical manifestations tends to be proportionate to the degree and duration of serum potassium reduction. Symptoms generally do not become present until serum potassium is below $3.0 \mathrm{mEq} / \mathrm{L}$, unless it falls rapidly or the patient has a potentiating factor, such as the use of digitalis, in which patients have a predisposition to arrhythmias. According to the severity of hypokalemia, symptoms can vary from absent to lethal heart arrhythmias (22). Symptoms usually resolve with correction of the hypokalemia.

More specifically, we could categorize the manifestations according to the affected system. The effects of hypokalemia regarding the renal function can be metabolic acidosis, rhabdomyolysis (in severe

Table 1 Causes of hypokalemia.

\begin{tabular}{|c|c|}
\hline Gastrointestinal tract losses & $\begin{array}{l}\text { - Chronic diarrhea, including chronic laxative abuse and bowel diversion } \\
\text { - Clay (bentonite) ingestion, which binds potassium and greatly decreases absorption } \\
\text { - Villous adenoma of the colon, which causes massive potassium secretion (rarely) }\end{array}$ \\
\hline Intracellular shift & $\begin{array}{l}\text { - Glycogenesis during total parenteral nutrition or enteral hyperalimentation (stimulating } \\
\text { insulin release) } \\
\text { - Insulin administration } \\
\text { - Stimulation of the sympathetic nervous system, particularly with beta 2-agonists (albuterol, } \\
\text { terbutaline) } \\
\text { - Thyrotoxicosis (occasionally) due to excessive beta-sympathetic stimulation (hypokalemic } \\
\text { thyrotoxic periodic paralysis) } \\
\text { - Familial periodic paralysis }\end{array}$ \\
\hline Renal potassium losses & $\begin{array}{l}\text { - Adrenal steroid excess (Cushing's syndrome) } \\
\text { - Primary hyperaldosteronism } \\
\text { - Rare renin-secreting tumors } \\
\text { - Glucocorticoid-remediable congenital adrenal hyperplasia. } \\
\text { - Ingestion of substances such as glycyrrhizin } \\
\text { - } \text { Bartter syndrome } \\
\text { - } \text { Gitelman syndrome } \\
\text { - Renal tubular acidosis } \\
\text { - Fanconi syndrome } \\
\text { - Hypomagnesemia }\end{array}$ \\
\hline Drugs & $\begin{array}{l}\text { - Thiazides } \\
\text { - Loop diuretics } \\
\text { - } \text { - Laxmotic diuretics } \\
\text { - Amphotericin B } \\
\text { - Antipseudomonal penicillins (carbenicillin) } \\
\text { - } \text { Penicillin in high doses } \\
\text { - Theophylline (both acute and chronic intoxication) }\end{array}$ \\
\hline
\end{tabular}

http://www.endocrineconnections.org

https://doi.org/10.1530/EC-18-0109 (c) 2018 The authors Published by Bioscientifica Ltd

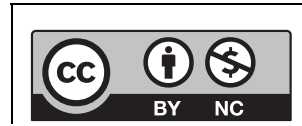

This work is licensed under a Creative Commons Attribution-NonCommercial 4.0 International License. 
hypokalemia) and, rarely, impairment of tubular transport, chronic tubulointerstitial disease and cyst formation. Nervous system is affected, the patient can suffer from leg cramps, weakness, paresis or ascending paralysis. Constipation or intestinal paralysis and respiratory failure often present as signs of severe hypokalemia. Last but not least, hypokalemia can have detrimental effects on the cardiovascular system, leading to electrocardiographic (ECG) changes (U waves, T wave flattening and ST-segment changes), cardiac arrhythmias (sometimes lethal) and heart failure (23) (Table 2).

\section{Laboratory investigation of hypokalemia}

\section{General diagnostic approach}

The underlying cause of hypokalemia is usually apparent after obtaining a detailed medical history and physical examination (24). In order to evaluate the severity of hypokalemia and to initiate an effective treatment, assessment of serum and urinary potassium levels is needed. Depending on the above findings, tests and imaging of the endocrine glands are appropriate, but they should not be first-line tests unless the clinical index of suspicion for such a disorder is high.

A basic biochemical laboratory panel (including serum sodium, potassium, glucose, chloride, bicarbonate, BUN and creatinine) is the core of screening in patients with hypokalemia. Urine electrolytes (potassium and chloride) in spot urine are useful in differentiating renal from non-renal causes of hypokalemia. An arterial blood gas (ABG) analysis should be performed to detect metabolic acidosis or alkalosis when the underlying cause is not apparent from the history. As the difference between arterial and vein blood samples, regarding the potassium levels, is clinically not significant, measurement of potassium in vein blood sample is not contraindicated in the emergency department. Further urinalysis and urine $\mathrm{pH}$ measurement should follow to assess for the presence of renal tubular acidosis. Serum magnesium, calcium and/or phosphorus levels are important to exclude associated electrolyte abnormalities, especially if alcoholism is suspected. Urinary calcium excretion is very critical to exclude Bartter syndrome. We should also measure serum digoxin level if the patient is on digitalis. In cases of high clinical index of suspicion for a disorder, a drug screen in urine and/or serum for diuretics, amphetamines and other sympathomimetic stimulants should be conducted. Assessment of TSH levels is required in cases of tachycardia or clinical suspicion of hypokalemic periodic paralysis (25).

In general, there are two major components of the diagnostic evaluation: (a) assessment of urinary potassium excretion in order to distinguish renal potassium losses (e.g., diuretic therapy, primary aldosteronism) from other causes of hypokalemia (e.g., gastrointestinal losses, transcellular potassium shifts) and (b) assessment of acid-base status, since some causes of hypokalemia are associated with metabolic alkalosis or metabolic acidosis. We present a diagnostic algorithm for the assessment of hypokalemia.

\section{Assessment of urinary potassium excretion}

Potassium excretion in a 24-h urine collection is the best way to assess the urinary potassium excretion (26). If this excretion is above $15 \mathrm{mEq}$ of potassium per day,

Table 2 Symptoms and signs of hypokalemia.

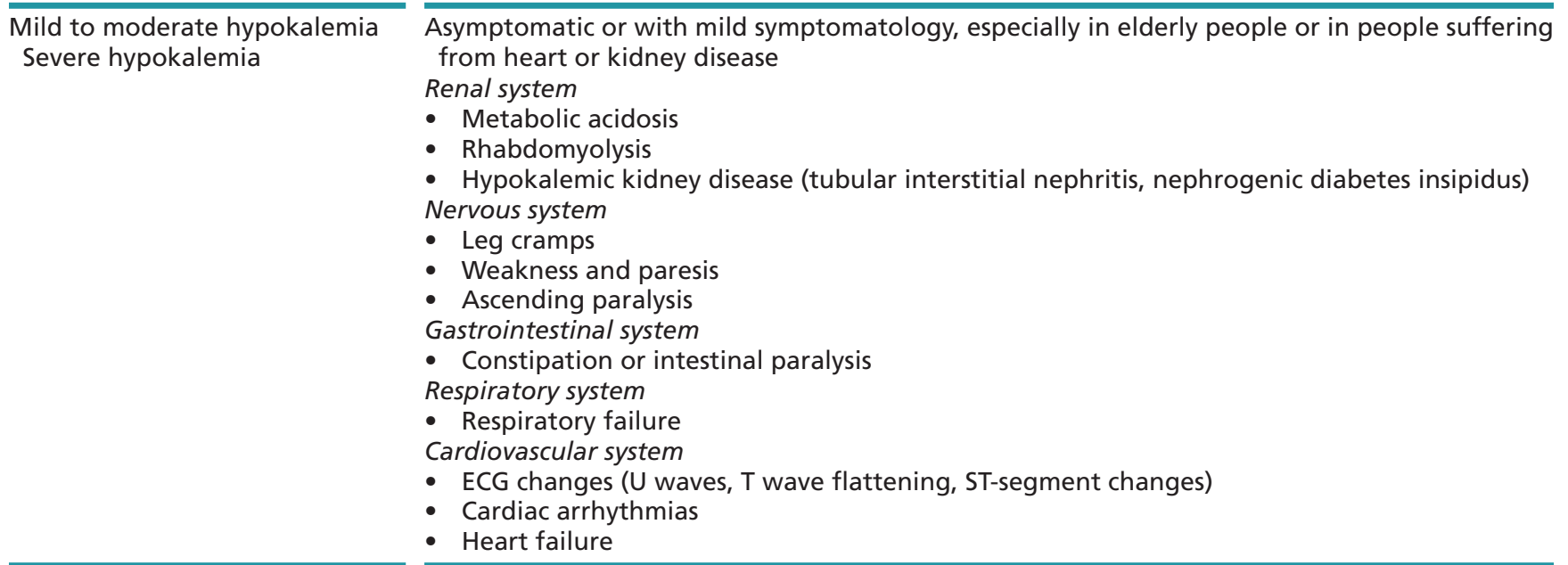


this is a direct indication of inappropriate renal potassium loss (27). Measurement of the potassium and creatinine concentrations in a spot urine is an alternative, if collection of a 24-h urine is not feasible. A spot urine potassiumto-creatinine ratio greater than $13 \mathrm{mEq} / \mathrm{g}$ creatinine $(1.5 \mathrm{mEq} / \mathrm{mmol})$ usually indicates inappropriate renal potassium loss. After determining whether renal potassium wasting is present, assessment of acid-base status can further narrow the differential diagnosis $(28,29)$.

\section{Assessment of acid-base status}

Once urinary potassium excretion is measured, the following diagnostic possibilities should be considered in the patient with hypokalemia of uncertain origin. A metabolic acidosis with a low rate of urinary potassium excretion in an asymptomatic patient is suggestive of lower gastrointestinal losses due to laxative abuse or a villous adenoma. On the other hand, a diabetic ketoacidosis or type 1 (distal) or type 2 (proximal) renal tubular acidosis can occur because of a metabolic acidosis with urinary potassium wasting. Furthermore, surreptitious vomiting (often common in bulimic patients trying to lose weight) or diuretic use can be the cause of a metabolic alkalosis with a low rate of urinary potassium excretion. In addition, some patients with laxative abuse present with metabolic alkalosis, rather than with the expected metabolic acidosis (30).

On the other side, when a metabolic alkalosis with urinary potassium wasting is present and the patient has a normal blood pressure, the diagnosis is diuretic use, vomiting, Gitelman or Bartter syndrome. In this setting, measurement of the urine chloride concentration is often helpful, being normal (equal to intake) in Gitelman or Bartter syndrome. On the other hand, urine chloride concentration is high or low with diuretics, depending upon the duration of action of the diuretic. In cases of vomiting, this concentration is low at a time when urinary sodium and potassium excretion may be relatively high due to the need to maintain electroneutrality as some of the excess bicarbonate is being excreted (31). In the presence of hypertension, a surreptitious diuretic therapy comes as first in the differential diagnosis in a patient with underlying hypertension, renovascular disease, or one of the causes of primary mineralocorticoid excess (32).

Patients with either Bartter or Gitelman syndrome may present with constipation, muscle cramps and weakness and non-specific dizziness and fatigue. The biochemical features of both syndromes can include hypokalemic,

$$
\text { http://www.endocrineconnections.org }
$$

hypochloremic metabolic alkalosis associated with high plasma renin activity and high aldosterone concentration (33). Patients with Bartter syndrome present in early childhood and the failure to thrive is more severe and with a great deal of growth retardation. Gitelman syndrome is associated with less severe failure to thrive and the growth retardation is milder. Symptoms of Gitleman syndrome are similar to thiazide diuretic-abusers with salt wasting. Indeed, Gitelman patients are mostly thought to be asymptomatic (34). They often present for workup of isolated, asymptomatic hypokalemia, but when closer questioned, $80 \%$ of Gitelman patients complain of dizziness and fatigue; $70 \%$ of the patients complain of muscle weakness and cramps and 50\% with nocturia and polyuria, in whom $90 \%$ are subsequently found to be salt wasters. Normal blood pressure in patients with Bartter syndrome is a feature thought to be different from the occasional hypotension of Gitelman syndrome. Focal segmental glomerulosclerosis has been described in Bartter syndrome (35). In contrast, Gitelman patients often complain of nocturia and polyuria. Persistent hypokalemia may give rise to interstitial nephritis, signaled by urinary anomalies. Urinary calcium excretion is important because it distinguishes the two syndromes. In contrast to the hypocalciuria of Gitelman syndrome, Bartter patients are often documented to have hypercalciuria. Medical noncompliance to potassium chloride supplementation and other therapy is an important issue in long-term follow-up of Bartter and Gitelman patients (36). Although the chronic hypokalemia can be mildly symptomatic, it can be aggravated by diarrhea or vomiting, precipitating prolonged QT interval, increased risk of rhabdomyolysis, cardiac arrhythmia, syncope and sudden death. Alcohol abuse, cocaine or other drug abuse can also precipitate lifethreatening arrhythmia electrolyte and fluid repair, oral potassium supplementation, potassium-sparing diuretics, cyclo-oxygenase inhibitors and renin-angiotensin blockers become life-saving in such emergencies (37). Finally, in familial cases, both conditions are conveyed by autosomal recessive transmission. The site of defect in Bartter syndrome is at the thick ascending limb (TAL) of the loop of Henle, whereas in Gitelman syndrome, the defect resides at the distal convoluted tubule (DCT) (38).

Liddle syndrome is a rare form of autosomal dominant hypertension with early penetrance and impressive cardiovascular sequelae. In addition to severe hypertension, many of the patients have overt hypokalemia. Despite having the clinical presentation typical of primary aldosteronism, the actual rates of aldosterone excretion are markedly suppressed, accounting

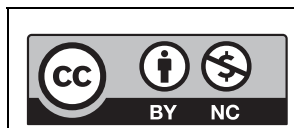

This work is licensed under a Creative Commons Attribution-NonCommercial 4.0 International License. 
for the descriptive term 'pseudoaldosteronism.' Liddle syndrome is an extreme example of low renin, volumeexpanded hypertension. In general, inappropriate renal Na1 retention with subsequent volume expansion, low plasma renin activity and hypertension are the consequences of 'pseudoaldosteronism' that results from constitutive activation of the amiloride-sensitive epithelial $\mathrm{Na} 1$ channel $(\mathrm{ENaC})$ in the terminal nephron segments. Cardiovascular and cerebrovascular complications of hypertension are much more common findings, and the usual cause of death in undiagnosed or untreated patients (39).

A diagnostic approach to a patient with hypokalemia is presented in Fig. 2.

\section{Endocrine causes of hypokalemia}

Screening for primary aldosteronism (PA) is recommended for any case with spontaneous or diuretic induced hypokalemia and hypertension. In such cases, a plasma aldosterone to plasma renin activity ratio (ARR) should be assessed. If it is higher than 20, further confirmatory testing is not necessary (oral sodium test, saline infusion test, fludrocortisone suppression test, captopril challenge test) (40). Conclusively, in case of patients with hypertension, who are at high risk for a primary hyperaldosteronism (patients with relatively high prevalence of $\mathrm{PA}$, including patients with stage I $>160-179 / 100-109 \mathrm{mmHg}$ ), stage II (>180/110 mmHg) or drug-resistant hypertension; hypertension with adrenal incidentaloma or hypertension and a family history of early-onset hypertension or cerebrovascular accident at age younger than 40 years), we should conduct a plasma aldosterone concentration/plasma renin activity ratio examination. An adrenal computed tomography scan is recommended in all patients with PA. This test also excludes large masses that may represent adrenocortical carcinoma. Moreover, adrenal venous sampling by an experienced radiologist is recommended to distinguish between unilateral and bilateral adrenal disease, when surgical treatment is feasible, and the patient is willing to undergo the procedure. Genetic testing for glucocorticoidremediable aldosteronsim (GRA) is suggested in patients, whose confirmed PA begins before 20 years of age and in those with a family history of PA or strokes at 40 years of age or younger. This condition is also called familial hyperaldosteronism type 1 . In very young patients with PA, testing for germline mutations in KCNJ5 is

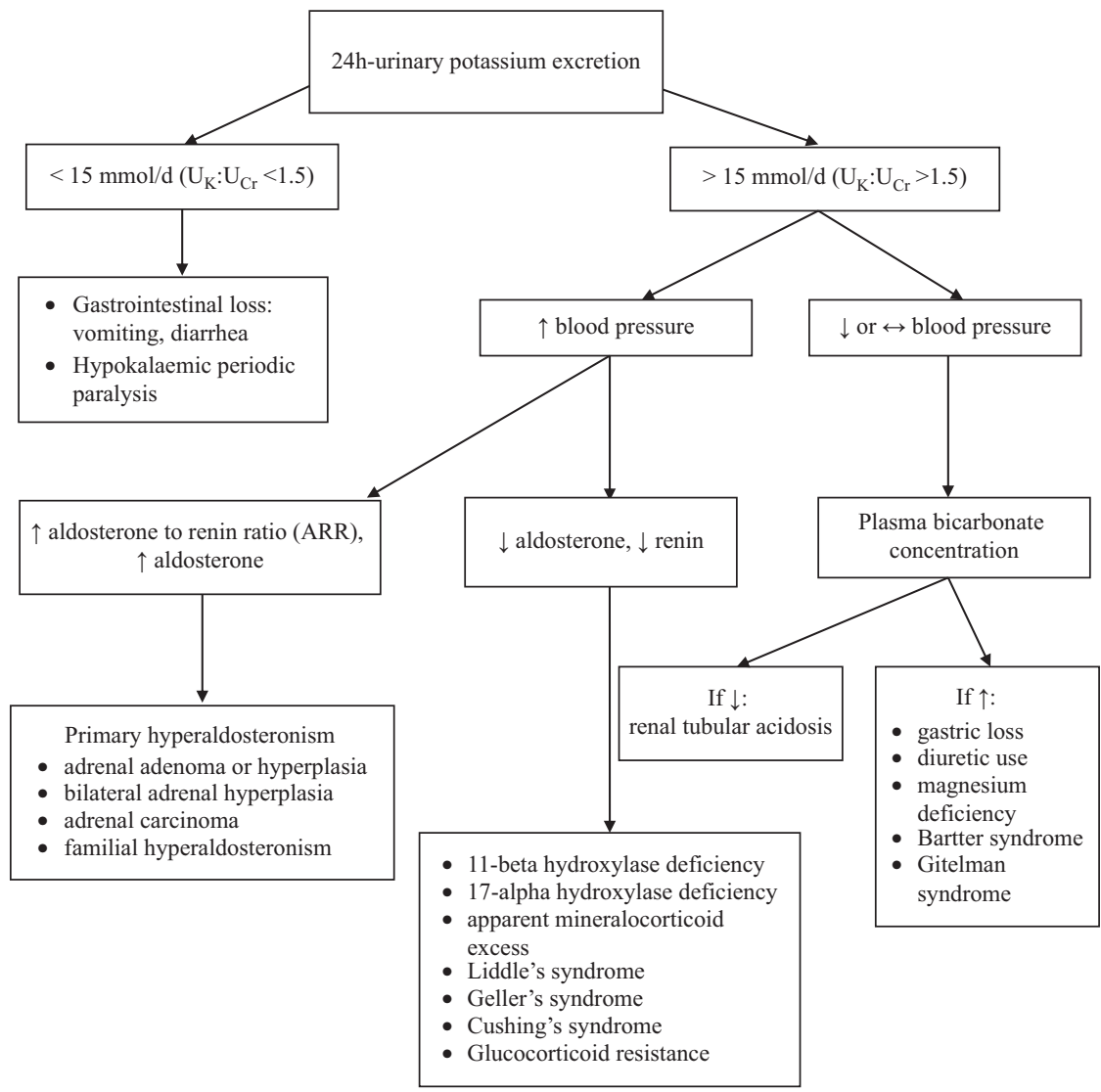

Figure 2

Algorithm of the diagnostic approach to a patient with hypokalemia. http://www.endocrineconnections.org https://doi.org/10.1530/EC-18-0109
() 2018 The authors Published by Bioscientifica Ltd

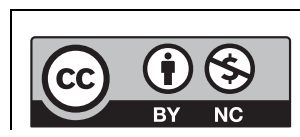

This work is licensed under a Creative Commons Attribution-NonCommercial 4.0 International License. 
recommended to diagnose familial hyperaldosteronism type 3 (41).

Rare causes of hypertension and hypokalemia include 11-beta hydroxylase and 17-alpha hydroxylase deficiency, which are characterized by increased production of cortisol and aldosterone precursors due to chronic stimulation of the adrenal cortex by ACTH (42). In 11-beta hydroxylase deficiency, 11-deoxycortisol is markedly elevated in the classic form, whereas in cases with the non-classic variants, 11-deoxycortisol may be normal and therefore an ACTH stimulation test is then indicated. In the classic form, deoxycorticosterone (DOC), urinary 17-ketosteroids, urinary tetra hydrometabolites, adrenal androgens, testosterone and 17-hydroxyprogesterone are elevated. On the contrast, in 17-alpha hydroxylase deficiency, 17-hydroxyprogesterone, 11-deoxycortisol cortisol, adrenal androgens and testosterone are all decreased or absent. The urinary metabolites 17-hydroxylase corticosteroid and 17-ketosteroid also are decreased or absent. The diagnosis is set by markedly elevated levels of 11-deoxycorticosterone and corticosterone (43). If there are clinical features of hypercortisolemia (e.g. Cushing's syndrome) and after excluding exogenous corticosteroid use, a diagnostic approach to confirm autonomous cortisol production is recommended. At least two of the following tests with high diagnostic accuracy is needed: 24-h urinary cortisol, late night salivary cortisol, $1 \mathrm{mg}$ overnight or $2 \mathrm{mg} 48$-h dexamethasone suppression test. In some cases, a serum midnight cortisol or dexamethasone-CRH test may be useful to establish the diagnosis of endogenous hypercortisolemia (44).

\section{Apparent mineralocorticoid excess}

Apparent mineralocorticoid excess (AME) is an autosomal recessive disease caused by deficiency of the enzyme 11betahydroxysteroid dehydrogenase type 2 (11beta-HSD2) (45). 11beta-HSD2 converts cortisol into inactive cortisone and prevents the stimulation of the mineralocorticoid receptor by cortisol. In patients with AME, an enhanced stimulation of mineralocorticoid receptors by cortisol in the distal nephron causes an elevated sodium reabsorption and increased potassium excretion. Sodium retention leads to severe low renin hypertension. The diagnosis of AME is based on the detection of an increased concentration of cortisol metabolites and a low or undetectable concentration of cortisone metabolites in urine (46). Molecular analysis of the HSD11B2 gene confirms the diagnosis. AME is successfully treated by potassium-sparing diuretics, sometimes in combination

$$
\text { http://www.endocrineconnections.org }
$$

with loop diuretics (furosemide). Mild forms of AME might occur more frequently than is currently known and should be suspected in patients with hypertension, hypokalemia and decreased plasma renin concentration. Since liquorice can induce the clinical symptoms of AME due to reversible inhibition of the 11beta-HSD2 enzyme by glycyrrhetinic acid, the active ingredient of liquorice, patients suspected of having AME should not consume liquorice (47).

\section{Glucocorticoid resistance syndrome}

Familial glucocorticoid (GC) resistance is a rare syndrome that is characterized by diminished cortisol action, which is mediated by the GC receptor (GR) (48). As a consequence, a compensatory stimulation of adrenocorticotropic hormone (ACTH) secretion by the pituitary occurs, resulting in elevated circulating levels of GCs, mineralocorticoids and androgens. This syndrome is inherited as an autosomal recessive or dominant disease. Several rare mutations of the GR gene (NR3C1) have been described, which were associated with clinical signs and symptoms of generalized GC resistance. In normal conditions, the secretion of GCs is regulated by the hypothalamus, which receives stimuli from the central nervous system. Due to GR defects, cortisol has impaired actions through the GR. As a consequence, the central negative feedback of GCs is diminished, GC production by the adrenal is elevated and cortisol binds with high affinity to the mineralocorticoid receptor (MR). Symptoms in patients with cortisol resistance are the consequence of this compensatory hyperactivity of the hypothalamus-pituitary-adrenal (HPA) axis (49). Due to elevated ACTH, patients suffer from an overproduction of mineralocorticoids, leading to hypertension, hypokalemic alkalosis and fatigue. Females also show signs of hyperandrogenism, such as hirsutism, male pattern of baldness and menstrual irregularities due to higher adrenal production of androgens. In males, the gonadal production of androgens is much higher, which outweighs the increased adrenal androgen production. In physiological conditions, tissues that have an important mineralocorticoid function (e.g. the kidneys) are protected from high cortisol levels by the enzyme 11b-hydroxysteroid dehydrogenase type II, which rapidly converts cortisol to the inactive cortisone. In the condition of cortisol resistance, cortisol levels exceed the capacity of this enzyme and thereby contribute to increased mineralocorticoid effects. However, GC-resistant patients can also be asymptomatic or suffer from chronic fatigue 
as the only complaint, which has been suggested to result from a relative GC deficiency due to insufficient compensation by the HPA axis. GCs have many functions in physiology and virtually all tissues are affected by them. These hormones are essential for cardiovascular and metabolic homeostasis and many functions of the central nervous system. Therefore, the syndrome of (partial) GC resistance is rare, and complete resistance to GCs is probably not compatible with life (50).

\section{Geller's syndrome (constitutive activation of the mineralocorticoid receptor)}

This is an autosomal dominant condition caused by gainof-function mutations in the MR located on chromosome $4 \mathrm{q} 31$. The onset of hypertension is before the age of 20 years. Pregnancy may exacerbate hypertension in patients with this condition because of elevated progesterone levels and altered specificity of the MR receptor with progesterone and traditional MR antagonists now acting as potent MR agonists. The biochemical profile includes normal potassium and low aldosterone, renin and urine aldosterone levels. Genetic testing of the MR is required, because a missense mutation S810L located in the hormone-binding domain of the MR has been found in patients, causing hypertension. Spironolactone, as a therapeutic choice, is contraindicated in MR-L810 carriers (51).

\section{Further testing}

Imaging

Imaging of the adrenal glands (computerized tomography (CT) or magnetic resonance (MRI)) if there is a suspicion of mineralocorticoid, glucocorticoid or catecholamine excess or MRI of pituitary gland (in order to exclude Cushing's disease) are useful in establishing the cause of hypokalemia. Moreover, an abdominal CT scan should be performed if clinical and laboratory features of VIPoma are present, such as watery diarrhea that persists with fasting (stools are tea-colored and odorless with stool volumes exceeding $700 \mathrm{~mL} /$ day), mild or absent abdominal pain, flushing episodes and lethargy, nausea, vomiting, muscle weakness and muscle cramps (in 20 percent of patients, where symptoms are related to hypokalemia and dehydration), if the CT is inconclusive, it may be necessary to perform radiolabeled pentetreotide scintigraphy or endoscopic ultrasound to confirm the diagnosis (52).

$$
\text { http://www.endocrineconnections.org }
$$

\section{ECG}

An ECG is recommended for all patients with hypokalemia. Typically, there is suppression of the ST segment, decrease in the amplitude of the $\mathrm{T}$ wave and an increase in the amplitude of $U$ waves (often seen in the lateral precordial leads V4 to V6). A variety of arrhythmias may be associated with hypokalemia, including sinus bradycardia, premature atrial and ventricular beats, paroxysmal atrial or junctional tachycardia, atrioventricular block, ventricular tachycardia or fibrillation (53).

\section{Treatment of hypokalemia}

The treatment of hypokalemia has four aims: (a) reduction of potassium losses, (b) replenishment of potassium stores, (c) evaluation for potential toxicities and (d) determination of the cause, in order to prevent future episodes, if possible. Major goal of treatment should be the management of the underlying disease or elimination of the causative factor. Discontinuation of laxatives, use of potassium-neutral or potassium-sparing diuretics (if diuretic therapy is required, such as in heart failure), treatment of diarrhea or vomiting, use of $\mathrm{H}_{2}$ blockers in patients with nasogastric suction and effective control of hyperglycemia, if glycosuria is present, are some measures in this direction (54).

Whether oral or intravenous potassium will be administered, this should be decided according the severity of the hypokalemia. It is important to remember that every $1 \mathrm{mEq} / \mathrm{L}$ decrease in serum potassium, represents a potassium deficit of approximately 200-400 mEq. However, this calculation could either overestimate or underestimate the true potassium deficit. Patients with potassium levels of $2.5-3.5 \mathrm{mEq} / \mathrm{L}$ (representing mild to moderate hypokalemia), may need only oral potassium replacement. If potassium levels are less than $2.5 \mathrm{mEq} / \mathrm{L}$, intravenous (i.v.) potassium should be given, with close follow-up, continuous ECG monitoring, and serial potassium levels measurements. The i.v. route should be also our choice in patients with severe nausea, vomiting or abdominal distress (55). In patients with renal impairment, potassium should be very cautiously replaced and the renal team should be also contacted, if the patient is on dialysis or has severe renal impairment. Administration of oral potassium should be accompanied with plenty of fluid (between 100 and $250 \mathrm{~mL}$ of water, depending on the form of the tablet of potassium) and is better to be given with or after meals (56). Regarding i.v. therapy, 0.9\% sodium

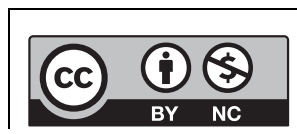

This work is licensed under a Creative Commons Attribution-NonCommercial 4.0 International License. 
Table 3 Treatment of hypokalemia.

$\begin{array}{ll}\text { Hypokalemia } & \begin{array}{l}\text { Treatment } \\ \text { Mild (3.0-3.4 mEq/L) }\end{array} \\ \begin{array}{l}\text { Potassium tablets }(72 \mathrm{mmol} / \mathrm{day}) \text { or } \\ \text { i.v. potassium infusion } 25 \mathrm{~mL} \\ (75 \mathrm{mmol} / \mathrm{day})\end{array}\end{array}$

Comments

- Usually asymptomatic

- Monitor potassium levels daily and adjust treatment accordingly

Moderate (2.5-2.9 mEq/L) Potassium tablets ( $96 \mathrm{mmol} / \mathrm{day})$ or

- Consider i.v. potassium if patient cannot tolerate oral potassium

- No or minor symptoms

- Monitor potassium levels daily and adjust treatment accordingly (100 mmol/day)

- Consider i.v. potassium if patient cannot tolerate oral potassium

Severe $(<2.5 \mathrm{mEq} / \mathrm{L}$ or symptomatic)
Intravenous replacement $40 \mathrm{mmol} \mathrm{KCl}$ - Standard infusion rate: $10 \mathrm{mmol} / \mathrm{h}$

in $1 \mathrm{~L} 0.9 \% \mathrm{NaCl}$ (glucose $5 \%$ may be - Maximum infusion rate: $20 \mathrm{mmol} / \mathrm{h}$ used)
- Check magnesium levels (reported automatically if $\mathrm{K}<2.8 \mathrm{mEq} / \mathrm{L})$

- If patient hypomagnesemic: initially give $4 \mathrm{~mL} \mathrm{MgSO}_{4}$ $50 \%(8 \mathrm{mmol})$ diluted in $10 \mathrm{~mL}$ of $\mathrm{NaCl} 0.9 \%$ over $20 \mathrm{~min}$, then start first $40 \mathrm{mmol} \mathrm{KCl}$ infusion, followed by magnesium replacement chloride is the preferred infusion fluid, as 5\% glucose may cause transcellular shift of potassium into cells. We should prefer pre/mixed i.v. infusions. It is critical also to correct the levels of serum magnesium, in order to achieve an adequate treatment of hypokalemia (57). An extensive description of the treatment of hypokalemia can be found in Table 3 .

\section{Conclusion}

In most patients presenting with hypokalemia, the cause is apparent from the history (e.g., vomiting, diarrhea, diuretic therapy). Two are the major components for the diagnostic evaluation: (a) assessment of urinary potassium excretion in order to distinguish renal potassium losses (e.g., diuretic therapy, PA) from other causes of hypokalemia (e.g., gastrointestinal losses, transcellular potassium shifts), and (b) assessment of acid-base status, since some causes of hypokalemia are associated with metabolic alkalosis or metabolic acidosis. The renal potassium excretion is better assessed by a $24-\mathrm{h}$ urine collection. However, the potassium concentration or, preferably, potassium-to-creatinine ratio on a spot urine are alternatives. Management of the underlying disease or contributing factors constitutes the cornerstone of therapeutic approach. Potassium should be gradually replaced, preferably by oral administration if clinically feasible. In cases of severe/symptomatic hypokalemia and cardiac complications, i.v. administration with continuous ECG monitoring is recommended. In some patients, such as in endocrine related hypokalemia cases, multidisciplinary diagnostic and therapeutic approach is needed.

\section{Declaration of interest}

The authors declare that there is no conflict of interest that could be perceived as prejudicing the impartiality of this review.

\section{Funding}

This work did not receive any specific grant from any funding agency in the public, commercial, or not-for-profit sector.

\section{References}

1 Ashurst J, Sergent SR, Wagner BJ \& Kim J. Evidence-based management of potassium disorders in the emergency department (digest). Emergency Medicine Practice 2016218.

2 Elliott TL Electrolytes: Potassium Disorders. FP Essentials 2017459 21-28.

3 Weir MR \& Rolfe M. Potassium homeostasis and renin-angiotensinaldosterone system inhibitors. Clinical Journal of the American Society of Nephrology 20105 531-548. (https://doi.org/10.2215/ CJN.07821109)

4 McDonough AA \& Youn JH. Potassium homeostasis: the knowns, the unknowns, and the health benefits. Physiology 201732 100-111. (https://doi.org/10.1152/physiol.00022.2016)

5 Houston MC \& Harper KJ. Potassium, magnesium, and calcium: their role in both the cause and treatment of hypertension. Journal of Clinical Hypertension 200810 3-11. (https://doi.org/10.1111/j.17517176.2008.08575.x)

6 Seifter JL \& Chang HY. Disorders of acid-base balance: new perspectives. Kidney Disease 20172 170-186. (https://doi. org/10.1159/000453028)

7 Van der Wijst J, Tutakhel OAZ, Bos C, Danser AHJ, Hoorn EJ, Hoenderop JGJ \& Bindels RJM. Effects of a high sodium-low potassium diet on renal calcium, magnesium, and phosphate handling. American Journal of Physiology: Renal Physiology 2018 [epub]. (https://doi.org/10.1152/ajprenal.00379.2017)

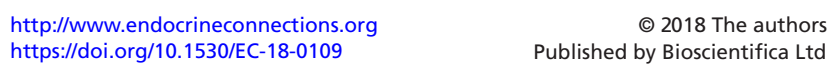

This work is licensed under a Creative Commons Attribution-NonCommercial 4.0 International License. 
8 Kamel KS, Schreiber M \& Halperin ML. Renal potassium physiology: integration of the renal response to dietary potassium depletion. Kidney International 201893 41-53. (https://doi.org/10.1016/j. kint.2017.08.018)

9 DuBose TD Jr. Regulation of potassium homeostasis in CKD Advances in Chronic Kidney Disease 201724 305-314. (https://doi. org/10.1053/j.ackd.2017.06.002)

10 Cohn JN, Kowey PR, Whelton PK \& Prisant LM. New guidelines for potassium replacement in clinical practice. Archives of Internal Medicine 2000160 2429-2436. (https://doi.org/10.1001/ archinte.160.16.2429)

11 Wang WH \& Giebisch G. Regulation of potassium (K) handling in the renal collecting duct. Pflügers Archiv 2009458 157. (https://doi. org/10.1007/s00424-008-0593-3)

12 Patel S, Rauf A, Khan H \& Abu-Izneid T. Renin-angiotensinaldosterone (RAAS): the ubiquitous system for homeostasis and pathologies. Biomedicine and Pharmacotherapy 201794 317-325. (https://doi.org/10.1016/j.biopha.2017.07.091)

13 Nguyen MT, Yang LE, Fletcher NK, Lee DH, Kocinsky H, Bachmann S, Delpire E \& McDonough AA. Effects of K+-deficient diets with and without $\mathrm{NaCl}$ supplementation on $\mathrm{Na}+, \mathrm{K}+$, and $\mathrm{H} 2 \mathrm{O}$ transporters' abundance along the nephron. Physiology-Renal Physiology 2012303 F92-F104. (https://doi.org/10.1152/ajprenal.00032.2012)

14 Dhondup T \& Qian Q. Acid-base and electrolyte disorders in patients with and without chronic kidney disease: an update. Kidney Disease 20173 136-148. (https://doi.org/10.1159/000479968)

15 Udensi UK \& Tchounwou PB. Potassium homeostasis, oxidative stress, and human disease. International Journal of Clinical and Experimental Physiology 20174 111-122. (https://doi.org/10.4103/ ijcep.ijcep_43_17)

16 Alfonzo AVM, Isles C, Geddes C \& Deighan C. Potassium disorders- clinical spectrum and emergency treatment. Resuscitation 200670 10-25. (https://doi.org/10.1016/j. resuscitation.2005.11.002)

17 Khitan ZJ, Shweihat YR, Tzamaloukas AH \& Shapiro JI. Dietary potassium and cardiovascular profile. Results from the modification of diet in renal disease dataset. Journal of Clinical Hypertension 2018 611-612. (https://doi.org/10.1111/jch.13207)

18 Gumz ML, Lynch IJ, Greenlee MM, Cain BD \& Wingo CS. The renal H+-K+-ATPases: physiology, regulation, and structure. American Journal of Physiology: Renal Physiology 2010298 F12-F21. (https://doi. org/10.1152/ajprenal.90723.2008)

19 Palmer BF, Perazella MA \& Choi MJ. American Society of Nephrology Quiz and Questionnaire 2013: electrolyte and acid-base. Clinical Journal of the American Society of Nephrology 20149 1132-1137. (https://doi.org/10.2215/CJN.11731113)

20 Patel K, McCoy JV \& Davis PM. Recognizing thyrotoxic hypokalemic periodic paralysis. JAAPA $20183131-34$.

21 Clausen T. Hormonal and pharmacological modification of plasma potassium homeostasis. Fundamental and Clinical Pharmacology 2010 24 595. (https://doi.org/10.1111/j.1472-8206.2010.00859.x)

22 Tran TTT, Pease A, Wood AJ, Zajac JD, Mårtensson J, Bellomo R \& Ekinci EII. Review of evidence for adult diabetic ketoacidosis management protocols. Frontiers in Endocrinology 20178106. (https://doi.org/10.3389/fendo.2017.00106)

23 Zacchia M, Abategiovanni ML, Stratigis S \& Capasso G. Potassium: from physiology to clinical implications. Kidney Disease 20162 72-79. (https://doi.org/10.1159/000446268)

24 Groeneveld JH, Sijpkens YW, Lin SH, Davids MR \& Halperin ML. An approach to the patient with severe hypokalaemia: the potassium quiz. QJM 200598 305. (https://doi.org/10.1093/qjmed/hci046)

25 Papademetriou V. Diuretics, hypokalaemia, and cardiac arrhythmia: a 20-year controversy. Journal of Clinical Hypertension $2006 \mathbf{8} 86$. (https://doi.org/10.1111/j.1524-6175.2005.04722.x)

26 Molin CZD \& Trevisol DJ. Persistent severe hypokalaemia: Gitelman syndrome and differential diagnosis. Jornal Brasileiro de Nefrologia $201739337-340$
27 Funder JW, Carey RM, Mantero F, Murad MH, Reincke M, Shibata H, Stowasser M \& Young WF Jr. The management of primary aldosteronism: case detection, diagnosis, and treatment: an Endocrine Society Clinical Practice Guideline. Journal of Clinical Endocrinology and Metabolism 2016101 1889-1916. (https://doi. org/10.1210/jc.2015-4061)

28 Thomas CP. Metabolic acidosis. In Medscape. Ed V Batuman. New York, NY, USA: WebMD LLC, 2017 (avalable at: https://emedicine. medscape.com/article/242975-overview)

29 Kovesdy CP, Appel LJ, Grams ME, Gutekunst L, McCullough PA, Palmer BF, Pitt B, Sica DA \& Townsend RR. Potassium homeostasis in health and disease: a scientific workshop cosponsored by the National Kidney Foundation and the American Society of Hypertension. Journal of the American Society of Hypertension 201711 783-800. (https://doi.org/10.1016/j.jash.2017.09.011)

30 Udensi UK \& Tchounwou PB. Potassium homeostasis, oxidative stress, and human disease. International Journal of Clinical and Experimental Physiology 20174 111-122. (https://doi.org/10.4103/ ijcep.ijcep_43_17)

$31 \mathrm{Wu}$ KL, Cheng CJ, Sung CC, Tseng MH, Hsu YJ, Yang SS, Chau T $\&$ Lin SH. Identification of the causes for chronic hypokalaemia: importance of urinary sodium and chloride excretion. American Journal of Medicine 2017130 846-855. (https://doi.org/10.1016/j. amjmed.2017.01.023)

32 Bailey A. How Should Intravenous Potassium Chloride be Administered in Adults Medicines Q\&A 186.2. Cardiff: Welsh Medicines Information Centre, 2008.

33 Fremont OT \& Chan JC. Cite as understanding Barter syndrome and Gitelman Syndrome. World Journal of Pediatrics 20128 25-30. (https://doi.org/10.1007/s12519-012-0333-9)

34 Seyberth HW, Weber S \& Kömhoff M. Bartter's and Gitelman's syndrome. Current Opinion in Pediatrics 201729 179-186. (https:// doi.org/10.1097/MOP.0000000000000447)

35 Kleta R \& Bockenhauer D. Salt-losing tubulopathies in children: what's new, what's controversial? Journal of the American Society of Nephrology 201829 727-739.

36 Filippatos TD, Rizos CV, Tzavella E \& Elisaf MS. Gitelman syndrome: an analysis of the underlying pathophysiologic mechanisms of acid-base and electrolyte abnormalities. International Urology and Nephrology 201850 91-96. (https://doi.org/10.1007/s11255-0171653-4)

37 Proesmans W. Threading through the mizmaze of Bartter syndrome. Pediatric Nephrology 200621 896-902. (https://doi.org/10.1007/ s00467-006-0113-7)

38 Seys E, Andrini O, Keck M, Mansour-Hendili L, Courand PY, Simian C, Deschenes G, Kwon T, Bertholet-Thomas A, Bobrie G, et al. Clinical and genetic spectrum of Bartter syndrome type 3. Journal of the American Society of Nephrology 201728 2540-2552. (https://doi. org/10.1681/ASN.2016101057)

39 Wang LP, Yang KQ, Jiang XJ, Wu HY, Zhang HM, Zou YB, Song L, Bian J, Hui RT, Liu YX, et al. Prevalence of Liddle syndrome among young hypertension patients of undetermined cause in a Chinese population. Journal of Clinical Hypertension 201517 902-907. (https://doi.org/10.1111/jch.12598)

40 Funder JW, Carey RM, Mantero F, Murad MH, Reincke M, Shibata H, Stowasser M \& Young WF Jr. The management of primary aldosteronism: case detection, diagnosis, and treatment: an Endocrine Society Clinical Practice Guideline. Journal of Clinical Endocrinology and Metabolism 2016101 1889-1916. (https://doi. org/10.1210/jc.2015-4061)

41 Farrugia FA, Zavras N, Martikos G, Tzanetis P, Charalampopoulos A, Misiakos EP, Sotiropoulos D \& Koliakos N. A short review of primary aldosteronism in a question and answer fashion. Endocrine Regulations 201852 27-40. (https://doi.org/10.2478/enr-2018-0005)

42 Hinz L, Pacaud D \& Kline G. Congenital adrenal hyperplasia causing hypertension: an illustrative review. Journal of Human Hypertension 201832 150-157. (https://doi.org/10.1038/s41371-017-0002-5) 
43 Auchus RJ. Steroid 17-hydroxylase and 17,20-lyase deficiencies, genetic and pharmacologic. Journal of Steroid Biochemistry and Molecular Biology 2017165 71-78. (https://doi.org/10.1016/j.jsbmb.2016.02.002)

44 El-Maouche D, Arlt W \& Merke DP. Congenital adrenal hyperplasia. Lancet 2017390 2194-2210. (https://doi.org/10.1016/S01406736(17)31431-9)

45 Zennaro MC, Boulkroun S \& Fernandes-Rosa F. Inherited forms of mineralocorticoid hypertension. Best Practice and Research: Clinical Endocrinology and Metabolism 201529 633-645. (https://doi. org/10.1016/j.beem.2015.04.010)

46 Yau M, Haider S, Khattab A, Ling C, Mathew M, Zaidi S, Bloch M, Patel M, Ewert S, Abdullah W, et al. Clinical, genetic, and structural basis of apparent mineralocorticoid excess due to $11 \beta$-hydroxysteroid dehydrogenase type 2 deficiency. PNAS 2017114 E11248-E11256. (https://doi.org/10.1073/pnas.1716621115)

47 Hassan-Smith Z \& Stewart PM. Inherited forms of mineralocorticoid hypertension. Current Opinion in Endocrinology, Diabetes and Obesity 201118 177-185. (https://doi.org/10.1097/MED.0b013e3283469444)

48 Koch CA \& Chrousos GP. Overview of endocrine hypertension. In Endotext. Eds LJ De Groot, G Chrousos, K Dungan, KR Feingold, A Grossman, JM Hershman, C Koch, M Korbonits, R McLachlan, M New, et al. South Dartmouth, MA: MDText.com, Inc., 2000. (available at: https://www.ncbi.nlm.nih.gov/books/NBK278980/)

49 Nicolaides NC \& Charmandari E. Chrousos syndrome: from molecular pathogenesis to therapeutic management. European Journal of Clinical Investigation 201545 504-514. (https://doi.org/10.1111/eci.12426)
50 Molnár Á, Patócs A, Likó I, Nyírő G, Rácz K, Tóth M \& Sármán B. An unexpected, mild phenotype of glucocorticoid resistance associated with glucocorticoid receptor gene mutation case report and review of the literature. BMC Medical Genetics 20181937.

51 Ferrari P \& Bianchetti MG. Diagnostic investigations in inherited endocrine disorders of sodium regulation. In Diagnostics of Endocrine Function in Children and Adolescents, 4th ed., pp 210-234. Eds MB Ranke \& PE Mullis. Basel, Switzerland: Karger, 2011.

52 Elsayes KM, Emad-Eldin S, Morani AC \& Jensen CT. Practical approach to adrenal imaging. Radiologic Clinics of North America 2017 55 279-301. (https://doi.org/10.1016/j.rcl.2016.10.005)

53 Chua CE, Choi E \& Khoo EYH. Changes of severe hypokalaemia. QJM 2018 [epub]. (https://doi.org/10.1093/qjmed/hcy046)

54 Marti G, Schwarz C, Leichtle AB, Fiedler GM, Arampatzis S, Exadaktylos AK \& Lindner G. Etiology and symptoms of severe hypokalaemia in emergency department patients. European Journal of Emergency Medicine 201421 46-51.

55 Sterns RH. Treatment of severe hyponatremia. Clinical Journal of the American Society of Nephrology 2018 [epub]. (https://doi.org/10.2215/ CJN.10440917)

56 Palmer BF. Regulation of potassium homeostasis. Clinical Journal of the American Society of Nephrology 201510 1050-1060. (https://doi. org/10.2215/CJN.08580813)

57 Ashurst J, Sergent SR \& Sergent BR. Evidence-based management of potassium disorders in the emergency department. Emergency Medicine Practice 201618 1-24.

Received in final form 10 March 2018

Accepted 14 March 2018

Accepted Preprint published online 14 March 2018 http://www.endocrineconnections.org

https://doi.org/10.1530/EC-18-0109
(C) 2018 The authors Published by Bioscientifica Ltd

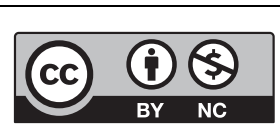

This work is licensed under a Creative Commons Attribution-NonCommercial 4.0 International License. 